\title{
AVALIAÇÃO DA MODIFICAÇÃO NA CONFIGURAÇÃO ESPACIAL DE CANOAS/RS COM O PROJETO DE IMPLANTAÇÃO DE LINHAS DE AEROMÓVEL
}

\author{
EVALUACIÓN DE LA MODIFICACIÓN EN LA CONFIGURACIÓN ESPACIAL EM LA CIUDAD DE CANOAS/ \\ RS CON EL PROYECTO DE IMPLANTACIÓN DE LÍNEAS DE TREM DE SUPERFICIE MOVIDO A AIRE
}

\author{
EVALUATION OF THE CHANGES IN THE SPATIAL CONFIGURATION OF THE CITY OF CANOAS/RS WITH \\ THE PROJECT OF IMPLEMENTATION OF AIR MOVED TRAIN LINES
}

\section{BALESTRO, FERNANDA}

Engenheira Ambiental, Mestre em Planejamento Urbano e Regional, UFRGS, febalestro@gmail.com

\author{
ZAMPIERI, FÁBIO LÚCIO \\ Doutor em Planejamento Urbano e Regional, Professor Adjunto na UFRGS, fabio.zampieri@ufrgs.br
}

\begin{abstract}
RESUMO
A proposição de traçado de modais de transporte público, como metrô e trens urbanos, deveria ser avaliada quanto às alterações espaciais que promove (como, entre outros, mudanças na integração e na acessibilidade), o que beneficiaria a cidade como um todo e a população diretamente envolvida. 0 presente artigo avalia as mudanças nas propriedades configuracionais das áreas contempladas com a proposta de implantação do aeromóvel pela prefeitura de Canoas/RS. Foram analisados dois cenários: a situação atual da cidade e com o aeromóvel implantado. 0 estudo teve como base a Teoria e os Métodos da Sintaxe Espacial, objetivando investigar se 0 traçado proposto traria ganhos do ponto de vista configuracional para o sistema urbano e para as regiões periféricas e de baixa renda do municipio lindeiras ao projeto. $O$ resultado da avaliação configuracional da cidade de Canoas mostrou que, se o projeto do aeromóvel fosse implantado, promoveria ganhos na acessibilidade geral, com uma real diminuição da distância topológica e da profundidade do sistema como um todo. Tais mudanças teriam potencial para trazer melhorias significativas para as condições de vida da população que hoje se encontra mais distante do centro e segregada espacialmente, sendo o bairro Guajuviras (o mais pobre e o mais segregado do município) a região com maior aumento na acessibilidade.
\end{abstract}

PALAVRAS-CHAVE: segregação espacial; sintaxe espacial; aeromóvel; transporte público.

\section{RESUMEN}

La propuesta de rutas de modos de transporte público, como el metro y los trenes urbanos, debe evaluarse en términos de los cambios espaciales que promueve, como la accesibilidad, que beneficiaría a la ciudad en su conjunto y a la población directamente involucrada. El presente estudio evalúa los cambios en las propiedades de configuración de las áreas contempladas con la propuesta de implantación del trem de superficie movido a aire por la ciudad de Canoas, Rio Grande do Sul. Se analizaron dos escenarios: la situación actual de la ciudad y con el avión desplegado. El estudio se basó en la Teoría y Métodos de Sintaxis Espacial, con el objetivo de investigar si la ruta propuesta traería ganancias desde el punto de vista configuracional para el sistema urbano y para las regiones periféricas y municipios de bajos ingresos que bordean el proyecto. Los resultados de la evaluación de la configuración de la ciudad de Canoas con el trem de superficie movido a aire mostraron que, si este proyecto se implementara, promovería ganancias en la accesibilidad general del sistema con una disminución real en la distancia topológica y la profundidad del sistema en su conjunto. Tales cambios tendrían el potencial de traer mejoras significativas a las condiciones de vida de la población que hoy está más alejada del centro y espacialmente segregada, siendo el vecindario de Guajuviras (el más pobre y más segregado del municipio) la región con el mayor aumento de accesibilidad.

PALABRAS CLAVE: segregación espacial; sintaxis espacial; trem de superficie movido a aire; transporte publico.

\section{ABSTRACT}

The proposal for the design of public transport modes, such as subways and urban trains, should be evaluated in terms of the spatial changes it promotes (such as, among others, changes in integration and accessibility), which would benefit the city as a whole and the population directly involved. The present study evaluates the changes in the configurational properties of the areas contemplated with the proposal of implantation of air moved train lines by the city of Canoas, Rio Grande do Sul. Two scenarios were analyzed: the current situation of the city and with the air moved train lines deployed. The study used the Theory and Methods of Space Syntax aiming to investigate whether the proposed route would bring gains from the configurational point of view for the urban system and for the peripheral regions and lowincome municipalities bordering the project. The results of the configurational analysis of the city of Canoas showed that, if the air moved train lines project were implemented, it would promote gains in general accessibility, with a real decrease in the topological distance and the depth of the system as a whole. Such changes would have the potential to bring significant improvements to the living conditions of the population that today is farther from the center and spatially segregated, with the Guajuviras neighborhood (the poorest and most segregated in the municipality) being the region with the greatest increase in accessibility.

KEYWORDS: spatial segregation; spatial syntax; air moved train lines; public transportation. 


\section{INTRODUÇÃO}

A cidade é um sistema de espaços conectados entre si por meio de uma rede de vias, através das quais as pessoas se deslocam de um ponto ao outro. Dentro deste sistema, as diferentes áreas da cidade não são servidas igualmente pelos serviços urbanos e, de forma geral, as áreas mais periféricas e pobres apresentam menor disponibilidade de serviços públicos como água, esgoto e transporte público (MARICATO, 2003). A carência de infraestrutura de mobilidade urbana afeta o cotidiano da população, uma vez que mover-se de um ponto a outro da cidade, ou entre cidades, é parte do essencial no curso do desenvolvimento das atividades diárias; ela atinge de forma mais severa a parcela da população que mais depende do sistema de transporte público e que, no Brasil, geralmente possui a renda mais baixa.

A carência em transporte público tem consequências práticas para a vida desta população mais pobre e mais periférica que, por residir em pontos mais distantes, emprega parte significativa do seu dia no deslocamento de e para o trabalho, comumente precisando de mais de um transporte para chegar ao seu destino, o que também implica maiores custos. Ainda, bairros que sejam muito segregados e com pouca acessibilidade diminuem o potencial econômico da região, uma vez que atividades comerciais dependem da facilidade da circulação de pessoas. Ou seja, as deficiências no sistema de transporte público transformam-se em um mecanismo de exclusão social, principalmente na periferia das regiões metropolitanas (YOUNG; AGUIAR; POSSAS, 2013, p. 10).

Não por acaso, o levantamento do IPEA que analisou os custos das famílias brasileiras com transporte no período entre 2003 e 2009, mostrou que, quanto mais baixa a renda, mais se usa o transporte público e menos o privado individual (CARVALHO; PEREIRA, 2012). Já o estudo de Young, Aguiar e Possas (2013) enfatizou as perdas econômicas geradas pelas deficiências em transporte público para o estado do Rio de Janeiro, chegando a estimativas entre 7,8 e 15,7 bilhões de reais ao ano, ou entre 1,9 e 3,8\% do PIB estadual. Ou seja, a população de mais baixa renda é a que mais se serve de transporte público e a mais prejudicada pelas deficiências no setor, fazendo sentido que iniciativas de melhorias nesse campo deem maior enfoque para atendimento das regiões onde tais populações residam. Do mesmo modo, Zampieri et al. (2007) constatam que quanto menor a renda maior é o uso do deslocamento a pé como modo de transporte, caracterizando que muitas vezes essa população não tem sequer condições para pagar pelo serviço público.

Entende-se que os vários espaços abertos públicos que compõem uma cidade criam um sistema de deslocamentos possíveis e que a forma como o arranjo desses espaços se configura parece ser mais importante para entender esses deslocamentos do que a análise dos mesmos isoladamente - pois se depreende as relações entre cada um deles e os demais, o que cria sistemas de facilidades ou restrições ao movimento de um para o outro (HILLIER; VAUGHAN, 2007). Às relações de cada espaço da cidade com todos os outros denomina-se 'configuração espacial', a qual é diferente para cada ponto do sistema e pode contribuir para que seja mais fácil ou mais difícil se deslocar pela malha. Portugal e Goldner (2003 apud CORTELETTI, 2015) afirmam que, se a configuração espacial da malha urbana interfere na forma como as pessoas se deslocam, o sistema de transporte público interfere diretamente na conexão dos núcleos de centralidade, acelerando ou prejudicando seus processos de desenvolvimento, e agindo como um indutor da expansão urbana.

A Política Nacional de Mobilidade Urbana (BRASIL, 2012) determina que as cidades devem priorizar os deslocamentos a pé e por meio de transporte coletivo acima das medidas de transporte individual. Os municípios, neste sentido, deveriam desenvolver seus Planos Municipais de Mobilidade Urbana, levando em consideração, além destes pressupostos, o atendimento equitativo de toda a população ao longo do seu território, e evitando áreas segregadas do sistema. Além disso, entende-se que, para melhorar e facilitar o acesso da população aos serviços urbanos, qualquer proposta de implantação de uma rede de transporte público deva estar bem articulada à malha urbana existente. Deve, ainda, funcionar como uma alternativa de trânsito rápido pela cidade, facilitando os deslocamentos das regiões periféricas até o centro. Neste sentido a presença de um novo modal de transportes irá criar um impacto no sistema de circulação urbano, seja ele positivo ou negativo, alterando a dinâmica do movimento das pessoas.

É dentro do contexto apresentado que este estudo está inserido. O município de Canoas, localizado na Região Metropolitana de Porto Alegre, Rio Grande do Sul, iniciou em 2012 a elaboração de um projeto para a implantação de linhas de aeromóvel (um tipo de veículo que circula em via elevada, semelhante a um trem), objeto desse estudo. O objetivo deste artigo é avaliar as mudanças nas propriedades espaciais das áreas contempladas com a proposta de implantação do aeromóvel em Canoas/RS - a Figura 1 apresenta a localização do aeromóvel na cidade e o comparativo entre os tempos de deslocamento por transporte público para o trecho da linha 1. Com base na Teoria e nos Métodos da Sintaxe Espacial, é analisada a atual configuração espacial da cidade e suas mudanças com a implantação do aeromóvel, para investigar se a proposição do traçado modifica a Integração e a acessibilidade das regiões periféricas e de baixa renda do município em relação à cidade, bem como verificar se há melhoria no sistema da cidade como um todo. 
Figura 1: Localização do aeromóvel e da linha 1 (em execução) em Canoas.

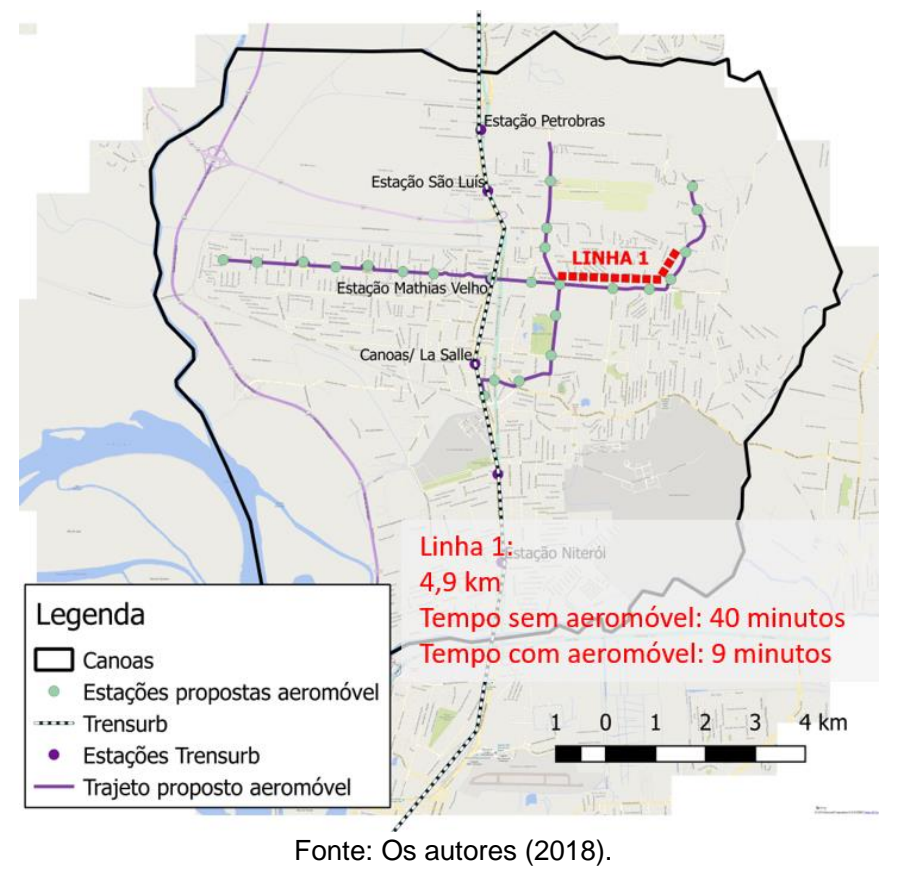

\section{SINTAXE ESPACIAL}

O presente estudo é baseado na Teoria da Sintaxe Espacial ${ }^{1}$ desenvolvida na década de 70 e cujo marco teórico-metodológico é o livro The social logic of space (1984), fruto de uma coautoria entre Bill Hillier e Julienne Hanson. Holanda (2002) conceitua a Sintaxe Espacial dizendo que:

concentra esforços nos aspectos denominados da co-presença, procurando, portanto, entender como o invólucro que cinge as pessoas interfere na maneira como elas se movem, param, encontram outras pessoas, como o espaço se conceitua como criador e regulador de comportamentos (HOLANDA, 2002, p. 78, grifo nosso).

Esta capacidade intrínseca da malha urbana de influenciar o movimento é denominada "movimento natural" (natural movement - HILLIER et al., 1993, p. 32) e está relacionada à configuração espacial, ou seja, à forma como os espaços estão relacionados entre si em um dado sistema, formando uma hierarquia. A sintaxe espacial permite avaliar a configuração do espaço e verificar a complexa relação entre qualquer par de espaços individuais em relação a outros espaços contextuais (HILLIER; VAUGHAN, 2007, p. 207), em outras palavras, a relação de um espaço aberto público a todos os outros do sistema.

Esta análise é feita tendo como base um modelo com uma abstração do sistema a ser analisado (que pode ser uma edificação, uma praça, uma cidade inteira etc.), representado, entre outros, como um mapa axial. Os mapas axiais avaliam as relações topológicas que se estabelecem entre os espaços abertos públicos, as quais desconsideram os atributos geométricos, como a distância, e buscam extrair e permitir uma visualização de como os espaços estão relacionados entre si. Logo, passos topológicos entre os pontos A e B contabilizam a quantidade de espaços pelos quais se deve passar para fazer o trajeto, independentemente da distância percorrida entre os mesmos.

Para o presente estudo considerou-se que o emprego da análise axial e da distância topológica entre os espaços é adequada para estudar esse modal de transporte público, uma vez que, dentro do traçado de um modal suspenso e sem depender da infraestrutura viária da cidade, o percurso entre estações não importa, dado que o usuário só pode entrar ou sair do mesmo nas estações. Semelhante consideração foi feita por Gil (2012) em um primeiro passo na análise de sistemas multimodais utilizando Sintaxe Espacial, pois cada estação se configura como um passo topológico.

A elaboração dos mapas axiais para análise é feita traçando-se o menor número de linhas retas que conectam os espaços públicos do sistema urbano (Figura 2). O resultado do mapa axial é apresentado por meio de um mapa, cujos valores de cada variável são representados para cada linha axial a partir de uma escala de cores, que variam entre o vermelho (o maior valor) até o azul (o menor). Esta forma de apresentação dos resultados, além de ser compreendida de forma intuitiva, permite que o sistema seja visualizado em sua totalidade. Pela leitura desses valores, pode-se, ainda, comparar o desempenho do sistema antes e depois de alguma 
alteração relevante na configuração espacial, como a construção de pontes, rodovias ou de um modal de transporte aéreo, enfoque deste trabalho. A sintaxe espacial trabalha com variáveis globais, que abrangem e comparam o sistema como um todo e variáveis locais, que comparam as linhas com seus vizinhos ou em raios de abrangência topológico locais.

Figura 2: Representação do espaço da cidade de Barnsbury (em branco estão as edificações) e mapa axial correspondente.
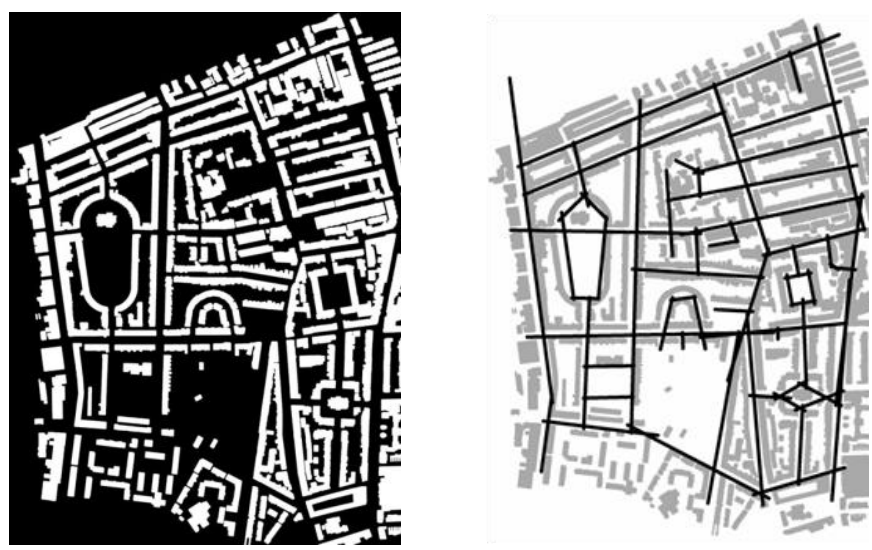

Fonte: UCL Space Syntax².

A partir da análise da configuração espacial de um sistema pode-se ter a noção de quais são os espaços mais integrados (mais rasos ou centrais) e mais segregados (mais profundos ou periféricos) do sistema. Esta avaliação, representada pela medida de Integração, permite ter ideia dos locais com maior probabilidade de fluxo de pedestres ou veículos (potencial de movimento): quanto menos profundo o espaço, mais integrado e acessível a todo o sistema ele está e, de modo inverso, quanto mais profundo mais segregado e menos acessível ele fica (HILLIER, 1993). A Integração, portanto, avalia a Centralidade de cada espaço, isto é, o quão fácil é de se chegar àquele ponto partindo-se de todos os outros pontos do sistema. Na cidade, essa condição está relacionada a consequências materiais, como uso do solo, densidade habitacional e fluxo de pedestres, entre outras.

Além do raio global, que abrange todo o sistema, é possível a avaliação de outros raios topológicos. Quanto maior o raio utilizado, maior a abrangência do deslocamento avaliado; já raios menores têm abrangência mais local, para a vizinhança que se pretende analisar. Por exemplo, a "Integração global" (Rn) (similar a variável de closeness) informa o grau de centralidade que um dado espaço (linha) tem com relação a cada uma das outras do sistema (que poderá ser uma região metropolitana, uma cidade, um bairro, uma edificação) (ZAMPIERI, 2012). Já a Integração Raio 3 (R3, ou seja, definida por três passos topológicos) apresenta boa correlação com movimento de pedestres (CUTTINI, 1999).

Vários estudos identificaram haver correlação entre o valor da Integração e o potencial de movimento de pedestres, com probabilidade de um maior número de pessoas passar por um segmento integrado do sistema (CUTTINI, 1999; HILLIER et al., 1993; JIANG, 2009). Os estudos também identificaram correlação de núcleos de Integração com localização de atividades comerciais, maior densidade demográfica, menor criminalidade e maior prosperidade (CUTTINI, 1999; HILLIER et al., 1993; UGALDE, 2013; VAUGHAN, 2007). Embora a configuração espacial influencie o movimento de pedestres pela malha, cabe dizer que os estudos não buscaram propor que a configuração espacial da malha urbana seja o principal ou o único gerador de movimento, mas, sim, que ela é o gerador primário (HILLIER et al., 1993, p. 31), ou seja, a configuração espacial por si só, influencia como as pessoas transitam pela cidade, como um pano de fundo sujeito a várias interações (HILLIER, 2007).

$\mathrm{Na}$ avaliação de modais aéreos e subterrâneos de transporte público, como trens, VLT, metrô e o aeromóvel, os estudos utilizando Sintaxe Espacial têm sido realizados de forma incipiente e recente (CHEN; KARIMI, 2019; GIL, 2012), integrando os mesmos à malha urbana e verificando seus efeitos sobre a configuração espacial em níveis local e global e potenciais consequências práticas decorrentes disto. Gil (2012) fez uma investigação inicial sobre como realizar a Integração de multimodais de transporte público, tendo utilizado a Sintaxe Espacial como base para a análise e, mais recentemente, Chen e Karimi (2019) a usaram para verificação do impacto da implantação de uma linha de metrô em Londres.

A presente pesquisa avaliou: (i) as medidas de Integração Global (Rn), para compreender os locais mais integrados e segregados da cidade e comparar com o cenário de existência do aeromóvel; (ii) a Integração Local R3 (três passos topológicos), que tem boa correlação com o movimento de pedestres e permite 
investigar centralidades locais e de bairro; (iii) a Sinergia, variável de análise do sistema inteiro obtida pela correlação entre a Integração Global (raio $n$ - que explica o movimento de pessoas por todo o sistema) e a Integração Local (que se refere ao movimento de pequeno alcance como do bairro ou mesmo da vizinhança) para todas as linhas. A Sinergia mede o grau em que a estrutura interna de uma área se relaciona com o sistema de maior escala em que está inserida (SPACE SYNTAX, 2019), e sua importância está em permitir o entendimento de quanto a lógica global pode ser entendida e replicada em nível local. Portanto, a avaliação configuracional do sistema e as alterações feitas com a implantação do aeromóvel permite que se tenha uma ideia das consequências em termos práticos dos resultados gerados. $O$ trabalho investigou a medida de Sinergia para dois raios diferentes de Integração Local - R3 (três passos topológicos) e R5 (cinco passos topológicos) - a fim de avaliar eventuais ganhos de potencial de movimento no sistema em escalas locais diferentes.

\section{PROPOSTA DE IMPLANTAÇÃO DO AEROMÓVEL EM CANOAS/RS}

O município de Canoas fica localizado no estado do Rio Grande do Sul, na Região Metropolitana de Porto Alegre, município com o qual faz divisa (Figura 3). Em 2018 sua população foi estimada em aproximadamente 344 mil habitantes (IBGE, 2018) distribuídos por uma área de $131 \mathrm{~km}^{2}$. Contando com universidades e uma refinaria de petróleo instaladas em seu território, Canoas apresenta o 4 maior PIB do Rio Grande do Sul, tendo importante contribuição na economia estadual (FEE, 2017). Sua divisão interna compreende 18 bairros (Figura 4), dos quais Guajuviras, Mathias Velho, Harmonia e Niterói são os mais populosos. Dentre estes, Guajuviras, Mathias Velho e Harmonia são, ainda, os bairros de menor renda per capita do município, e Guajuviras também apresenta os maiores índices de violência.

Figura 3: Localização do município de Canoas.

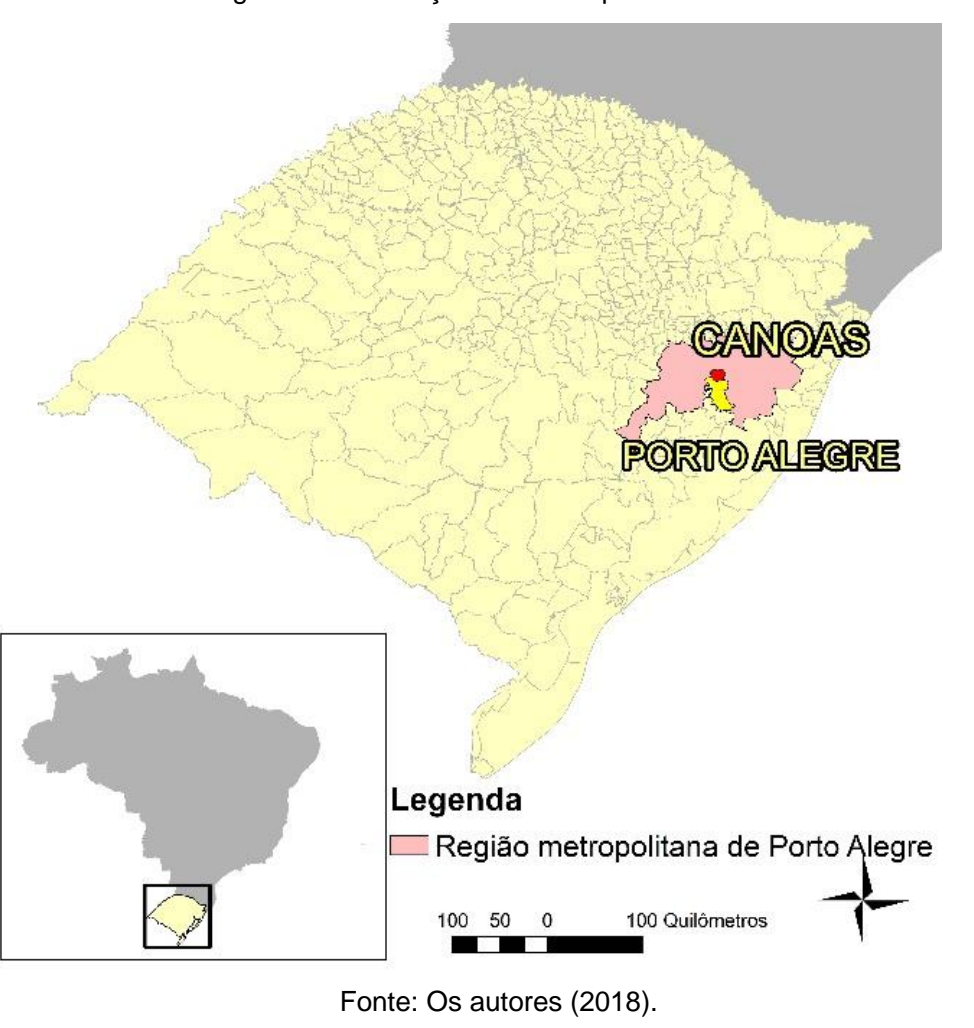

Em 2012 o município iniciou estudos técnicos para a implantação de um aeromóvel em seu território. Conforme é possível observar na Figura 4, o traçado proposto passa pelos bairros mais populosos e que apresentam menor renda per capita de Canoas, cujas populações costumam depender de transporte público para seus deslocamentos diários. O projeto final contemplou, ao todo, 18 quilômetros de linhas, passando por 24 estações, com capacidade prevista de $12 \mathrm{mil}$ passageiros/hora no pico e $82 \mathrm{mil}$ passageiros/dia (AEROMÓVEL, [s.d.]). 
Figura 4: Mapa de renda e de população por bairro de Canoas e traçado proposto do aeromóvel

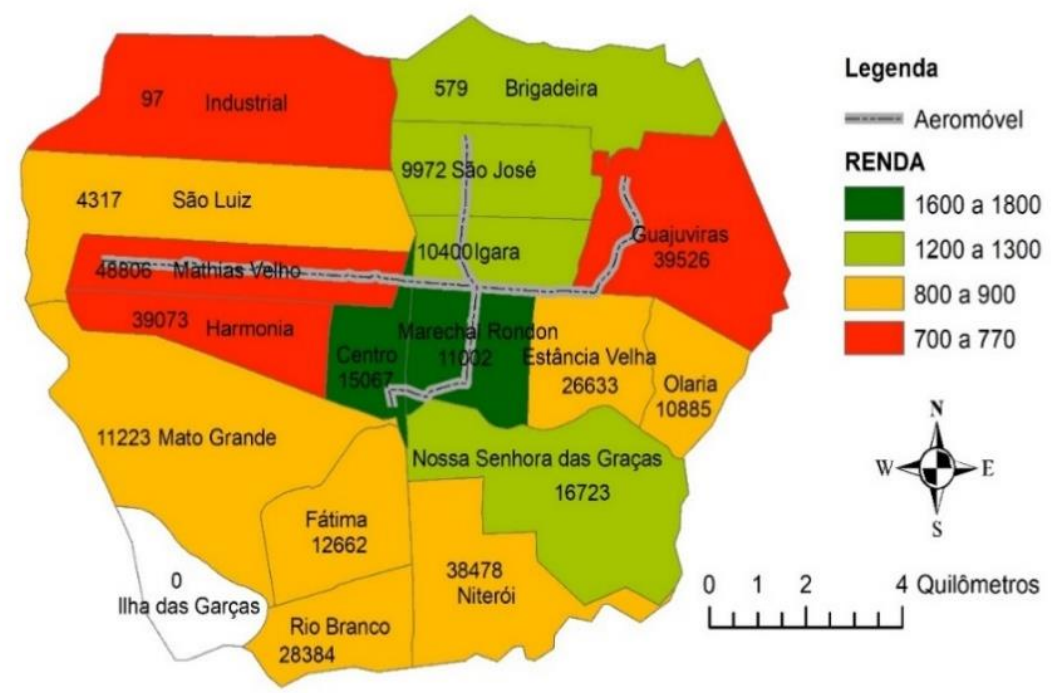

Fonte: Os autores, com base em dados do Instituto Canoas XXI. ${ }^{3}$

A Figura 5 apresenta uma representação esquemática do projeto proposto e da Linha 1, cuja execução foi iniciada. O projeto foi aprovado pelo governo federal em 2013, o qual se comprometeu a repassar verba de $\mathrm{R} \$ 272$ milhões. As avaliações técnicas operacionais foram feitas pelo Ministério das Cidades e pela Caixa Econômica Federal, que financiou o empreendimento. O contrato para a execução do primeiro trecho foi firmado em outubro de 2014 e as obras tiveram início em junho de 2015 para a linha 1, que ligaria a estação Mathias Velho do Trensurb ao bairro Guajuviras e atenderia 60 mil passageiros por dia.

Figura 5: Representação esquemática do trecho contratado para execução do aeromóvel.

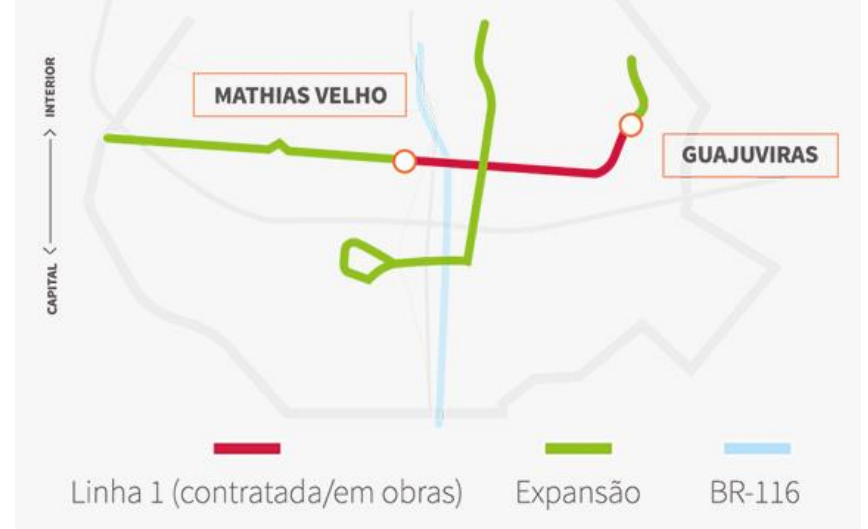

Fonte: Aeromóvel (2019). ${ }^{4}$

A linha 1 foi a primeira fase contratada do aeromóvel e suas obras já haviam sido iniciadas. A mesma faria a ligação do Guajuviras (um dos bairros mais populosos e mais pobres de Canoas) à região central, e teria o potencial de diminuir o tempo de deslocamento diário das populações diretamente atingidas (a empresa detentora do projeto estimava que, em horário de pico, o percurso na linha licitada passaria de 40 minutos para 9 minutos). Em sua totalidade, o projeto também contemplaria Mathias Velho e Harmonia (outros dois bairros pobres e populosos da cidade), com possíveis impactos relevantes em indicadores sociais da região, como diminuição do tempo gasto entre as viagens (liberado para outras atividades), poluição do ar e congestionamentos nas vias.

O projeto, no entanto, não teve seguimento. A obra foi paralisada em 2016, em função de múltiplos fatores: troca de gestão municipal; processo judicial promovido pela empreiteira que ficou em segundo lugar na licitação; e questionamentos da METROPLAN ${ }^{5}$, órgão de planejamento regional do estado, que se manifestou contra as obras por afirmar que aquele modal (aeromóvel) se configura como transporte metropolitano e, por isso, seu planejamento dependeria de um aval do órgão. Até sua paralização cerca de 67 milhões de reais já 
haviam sido investidos na obra; o futuro do aeromóvel e do dinheiro público investidos permanece incerto, pelo menos até o momento da publicação deste artigo.

\section{METODOLOGIA}

\section{Definição do tamanho do sistema a ser avaliado}

O presente estudo gerou dois diferentes mapas para análise: um que considera a situação atual e outro que utiliza este mapa como base e acrescenta o traçado proposto do aeromóvel para analisar as diferenças na configuração espacial que adviriam de sua implantação. O tamanho do sistema a ser analisado é relevante dentro do campo da sintaxe espacial devido ao chamado "efeito de borda" onde a periferia do mapa estará mais segregada por conta do tamanho do sistema, fato que pode ser indesejado à questão que o pesquisador deseja avaliar (GIL, 2015; VAUGHAN, 2007). Como no presente estudo se desejou avaliar a configuração espacial e entender a situação do sistema interno da cidade, o recorte respeitou o limite municipal, contemplando apenas o município de Canoas.

\section{Geração do mapa axial para a situação atual}

Os mapas axiais utilizados foram criados em 2009 para uma pesquisa de Rigatti e Zampieri (2009), tendo como base os mapas fornecidos pela Prefeitura de Canoas. Reconhece-se que a data de elaboração do mapa axial é uma limitação do presente estudo, pois, desde então, a cidade evoluiu com adição de novas ruas. Este mapa foi examinado e verificou-se apenas a adição de vias locais. Considerou-se que essas alterações no interior da malha viária não são significativas ao ponto de prejudicarem a análise configuracional que se pretende realizar, uma vez que não foram estabelecidas novas vias de ligação de grande fluxo, que poderiam deslocar centralidades. A este mapa axial base de Canoas foi acrescida a linha de trem metropolitano Trensurb, que atravessa a cidade de Canoas, para compor o primeiro mapa a ser analisado. As estações do mesmo foram mapeadas em ambiente SIG e entre elas foi traçada uma linha para uni-las e outras para conectá-las com a cidade. Nesta representação cada estação representa um passo topológico no sistema e é apenas nestes pontos que a linha de trem tem sua união com o restante da malha viária. Para todo o restante dos pontos em que a linha de trem corta o sistema foram colocados unlinks, ou seja, desconexões em forma de pontos na malha que mesmo que as linhas se cruzam em nível, não há ligação efetiva entre elas, como, por exemplo, o caso de viadutos ou e túneis. O mapa axial gerado para a situação atual acrescido da linha do Trensurb e todos os unlinks considerados está apresentado na Figura 6.

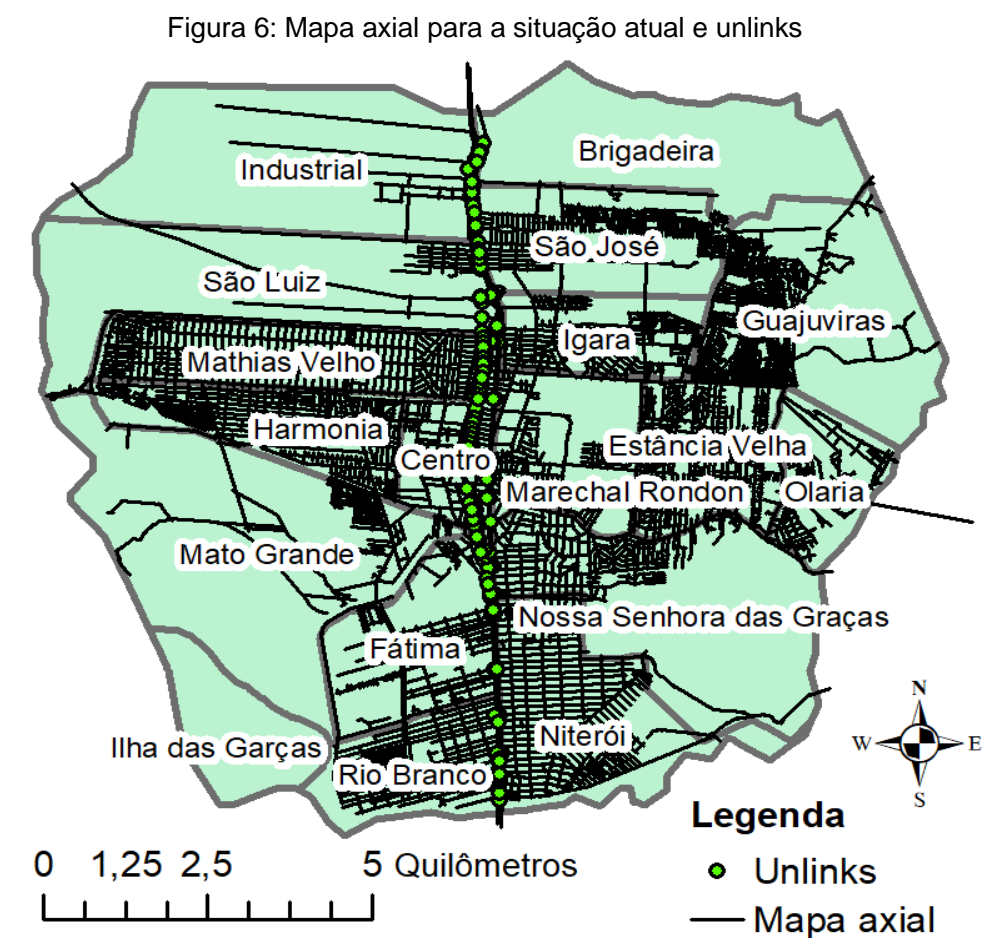

Fonte: Os autores (2018). 


\section{Geração do mapa axial para a situação com o aeromóvel}

O segundo mapa axial elaborado teve como ponto de partida o anterior, reformulado para a situação atual. A este mapa foi acrescido o traçado projetado do aeromóvel, obtido com base nos documentos disponibilizados pela Prefeitura de Canoas e acrescido ao mapa utilizando ambiente SIG, com o mesmo tratamento dispensado à linha da Trensurb. As estações propostas para o aeromóvel foram identificadas no mapa em uma camada de pontos, onde cada estação representa um passo topológico no mapa axial. Dado que, ainda que o traçado em via elevada acompanhe o desenho da via, os únicos pontos de ligação real com o sistema são as estações, os pontos que representam as mesmas foram interligados por uma linha, cuja conexão à malha viária foi feita apenas nos pontos onde há estações. O restante dos cruzamentos de linhas foi identificado como pontos de unlinks (desconexões). A Figura 7 apresenta o mapa axial para a situação atual, acrescido da linha do aeromóvel e todos os unlinks considerados.

Figura 7: Mapa axial para a situação com o aeromóvel e unkinks

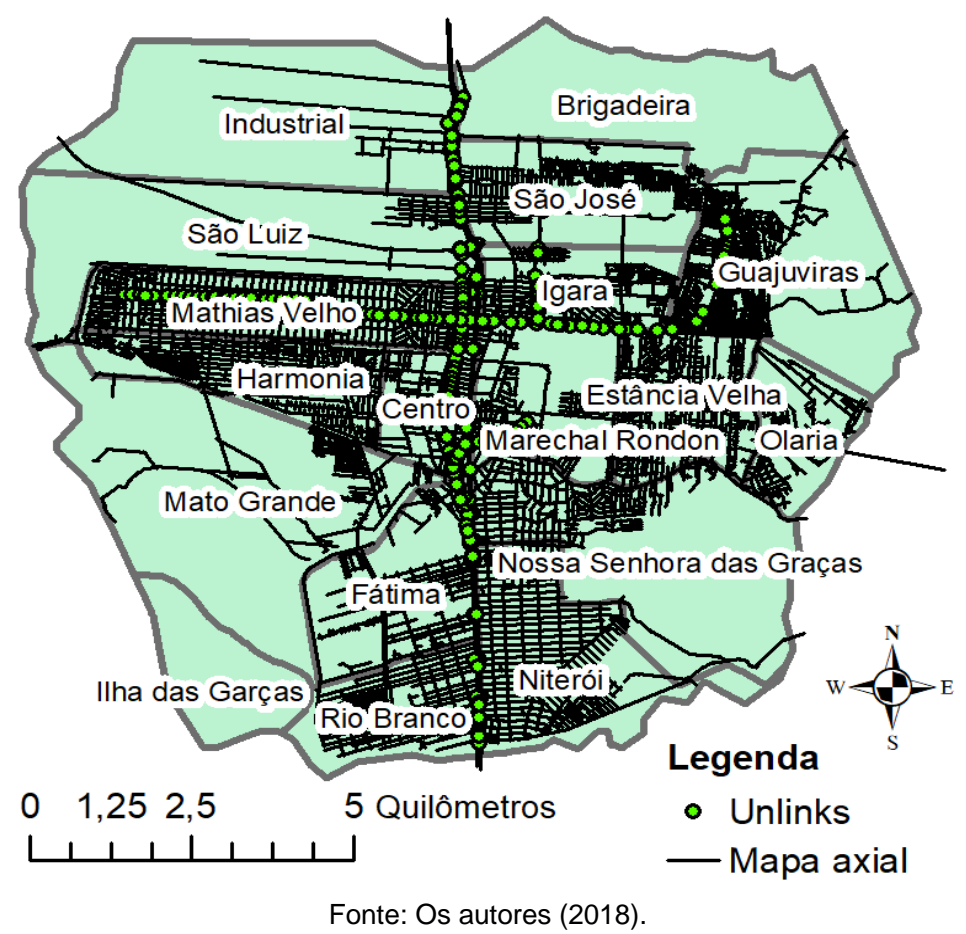

\section{Correção e processamento dos mapas}

Os mapas representativos dos dois cenários avaliados (situação atual e situação projetada com o aeromóvel) e ambas as camadas de unlinks foram verificados através de operações em GIS com auxílio do plugin Space Syntax Toolkit (GIL et al., 2015) para localização e correção de erros. O mapa axial final e corrigido teve seu processamento realizado por meio dos algoritmos do programa DepthmapX 0.35.

\section{RESULTADOS E DISCUSSÃO}

\section{Integração global}

A avaliação da Integração global do sistema permite visualizar e compreender o sistema urbano verificando as áreas mais integradas e segregadas em relação ao todo. Nas figuras 8 e 9 são apresentados os resultados da avaliação da Integração global para a situação atual (Figura 8) e para a situação com o aeromóvel (Figura 9), lembrando que a escala de cores varia de tons de azul escuro (segregado) para tons de vermelho (integrado). A avaliação do sistema mostra que houve melhora na Integração global do sistema com a implantação do aeromóvel. Pontualmente, houve uma melhora significativa na Integração do bairro Guajuviras, observada pela diminuição de linhas axiais com tons de azul escuro e avanço de linhas axiais mais integradas, com tons de verde e amarelo. O mesmo ocorre em direção aos bairros Mathias Velho e Harmonia, onde um trecho da linha do aeromóvel figura em destaque. Considera-se que a melhoria na Integração do bairro Guajuviras é bastante relevante, dado que este bairro é o mais segregado do sistema original. 
Estatisticamente, a média dos valores de Integração para as linhas axiais do sistema passou de 0,87 para 0,91, um ganho de aproximadamente $5 \%$, do mesmo modo, os valores máximos passaram de 1,53 para 1,62. Em termos práticos, isto quer dizer que com a implantação das linhas projetadas de aeromóvel, a cidade de Canoas passa a compor um sistema mais integrado com maior facilidade de locomoção interna, com caminhos mais curtos entre os espaços do sistema. Conforme discutido anteriormente, esta melhora verificada globalmente para bairros que se encontram na periferia e apresentam baixa renda é especialmente importante para as pessoas que ali residem.

Figura 8: Integração Global situação atual.

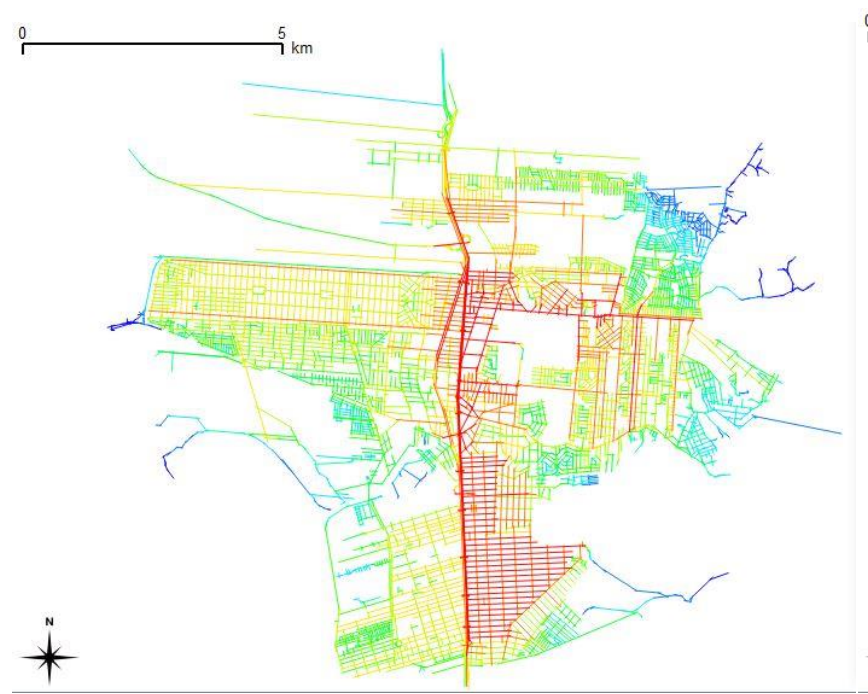

Figura 9: Integração Global com aeromóvel.

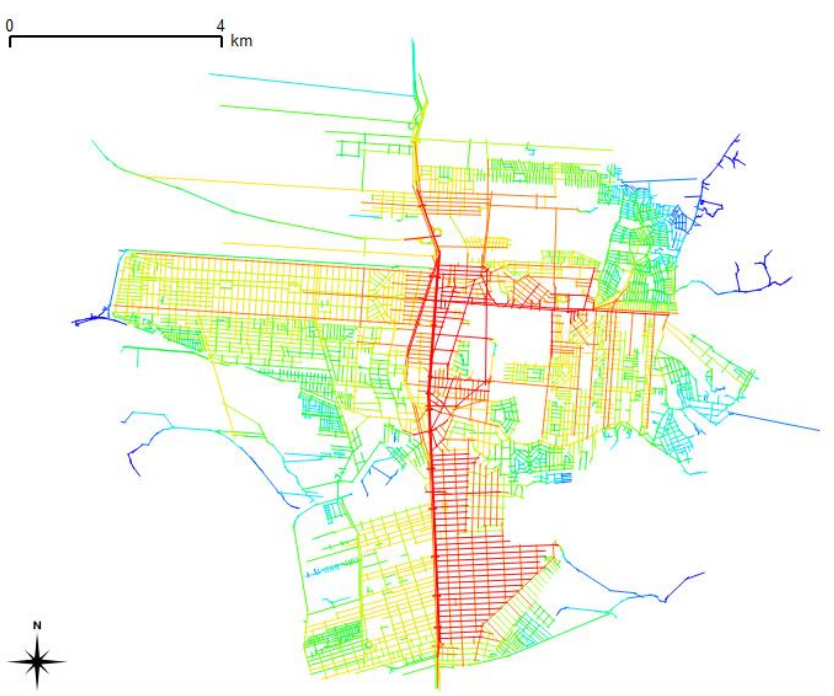

Fonte: Os autores (2018).

\section{Integração local R3}

Conforme citado anteriormente, a Integração local R3 (que mede a Integração até três passos topológicos) é reconhecida como uma medida adequada para a avaliação do movimento local de pedestres (CUTTINI, 1999; VAUGHAN, 2007). A avaliação da mesma permite verificar quais vias têm maior potencial de movimento local do pedestre para deslocamentos em pequena escala (tais como ir à escola e ao comércio local), dentro de seu bairro. Também destacam as vias com maior centralidade local. As figuras abaixo retratam os mapas de Integração local para a situação atual (Figura 10) e para a situação com o aeromóvel (Figura 11). Tais núcleos são vias preferenciais para o estabelecimento de contato entre os moradores e estranhos e para 0 estabelecimento de núcleos comerciais de bairro, uma vez que vias mais integradas apresentam correlação positiva com relação ao número de pessoas circulando.

Dentro da área de influência direta do aeromóvel, a mudança mais significativa é no bairro Guajuviras o qual passa a contar com um núcleo de Integração de bairro, identificado pela via em vermelho que se destaca, antes inexistente (Figura 12 e Figura 13). Este núcleo integrado é uma centralidade local, essencial para o desenvolvimento da vitalidade do bairro, dada a maior probabilidade de fluxo de pedestres. A presença de uma via integradora no bairro promove maior possibilidade de presença de pessoas e menor profundidade topológica no subsistema. Van Nes et al. (2013, p. 7) observaram que essa situação pode contribuir, inclusive, com a redução da criminalidade. Considerando estes indícios e, ainda, a constatação de Portugal e Gardner (2003 apud CORTELETTI, 2015) de que os núcleos de centralidade são indutores do desenvolvimento urbano, para a região seria desejável a fomentação de uma centralidade local, dadas as possibilidades que poderiam advir com isso. 


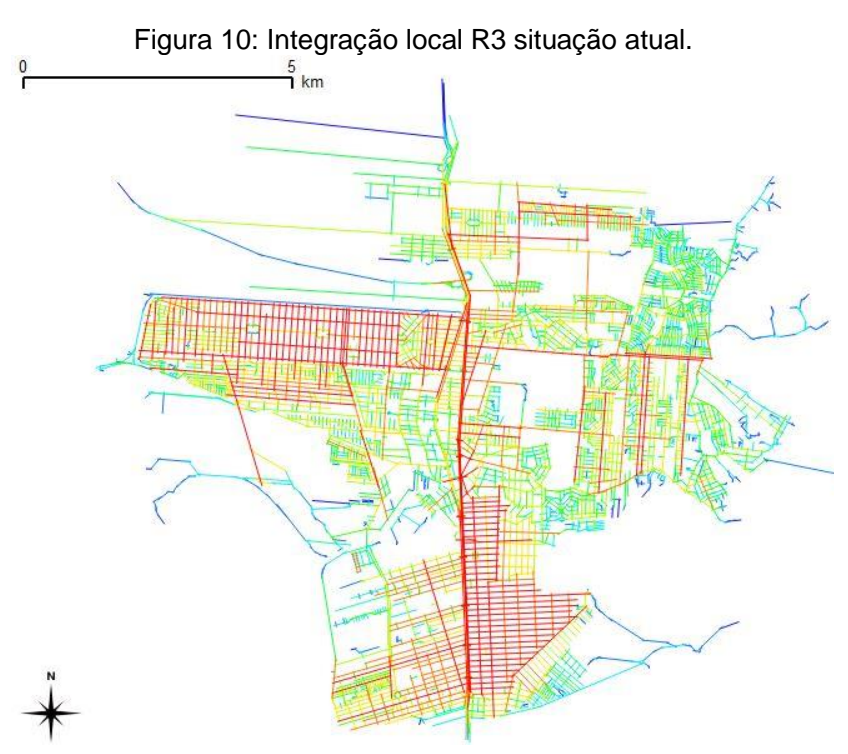

Figura 12: Integração local R3 situação atual para o bairro Guajuviras.

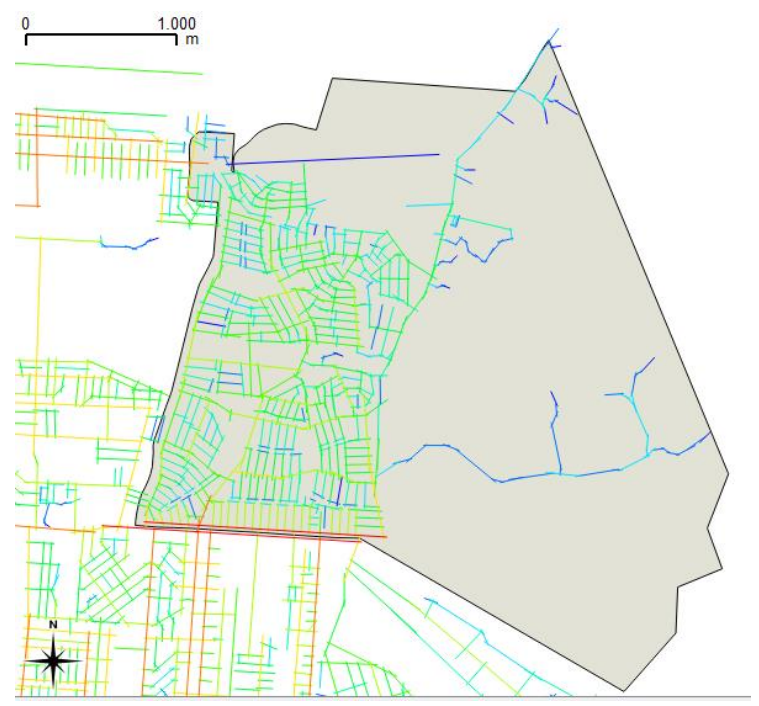

Figura 11: Integração local R3 com aeromóvel.

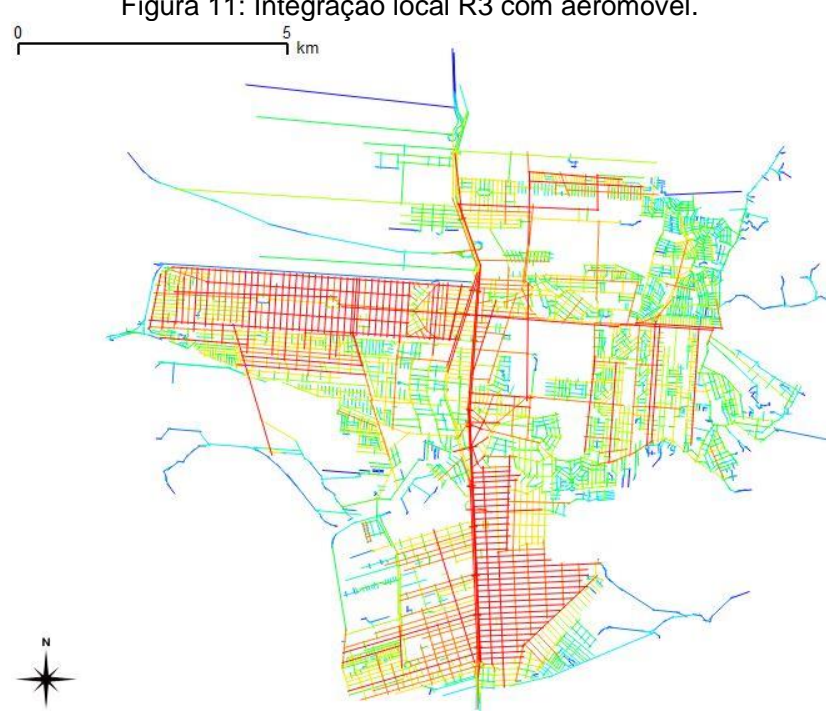

Figura 13: Integração local R3 com aeromóvel para o bairro Guajuviras.

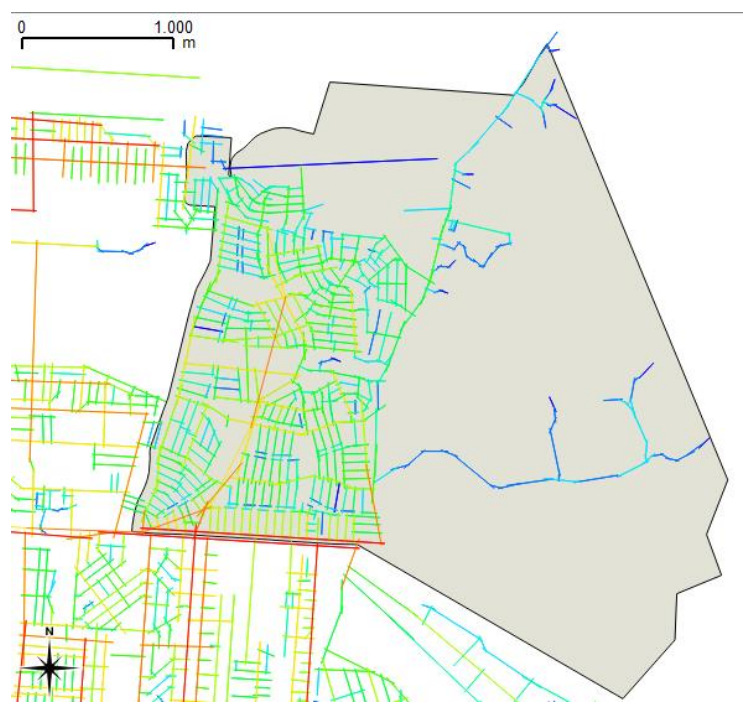

Fonte: Os autores (2018).

\section{Sinergia}

A avaliação da Sinergia de um sistema representa o quanto um pedestre, ao se locomover pelo mesmo, consegue perceber bem ambas as escalas, local e global (ZAMPIERI, 2006, p. 231), ou seja, o quanto a escala local explica a global e vice-versa. Quanto maior a Sinergia de um sistema, mais a cidade possui associação entre as centralidades e consequentemente o movimento global e local. A avaliação da Sinergia é feita pela plotagem dos valores de Integração local pelos valores de Integração global para todas as linhas axiais. Uma Sinergia mais alta quer dizer que as linhas axiais são integradas tanto localmente quanto globalmente. Pode-se ter um sistema no qual as vias mais integradas globalmente não apresentem tantos núcleos integrados de bairros. As figuras 14, 15, 16 e 17 mostram a situação para a Sinergia antes e após o aeromóvel. 
Figura 14: Integração local R3 situação atual.

Sinergia R3 - Sistema sem aeromóvel

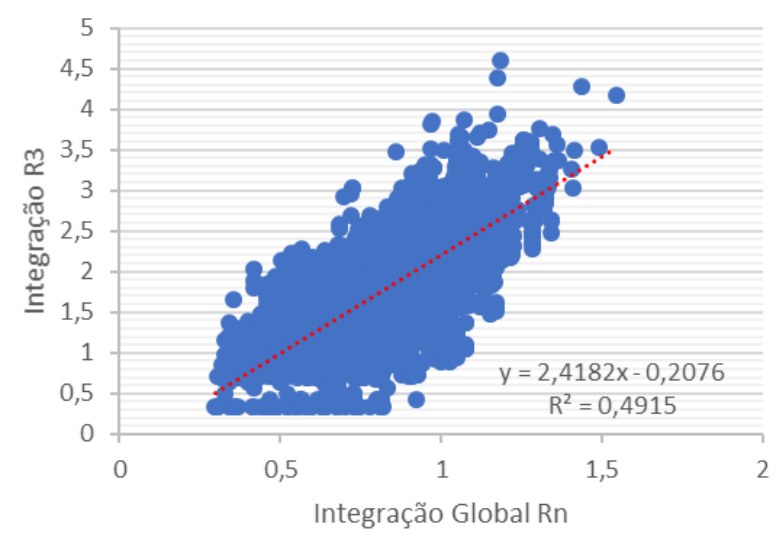

Figura 16: Integração local R5 situação atual.

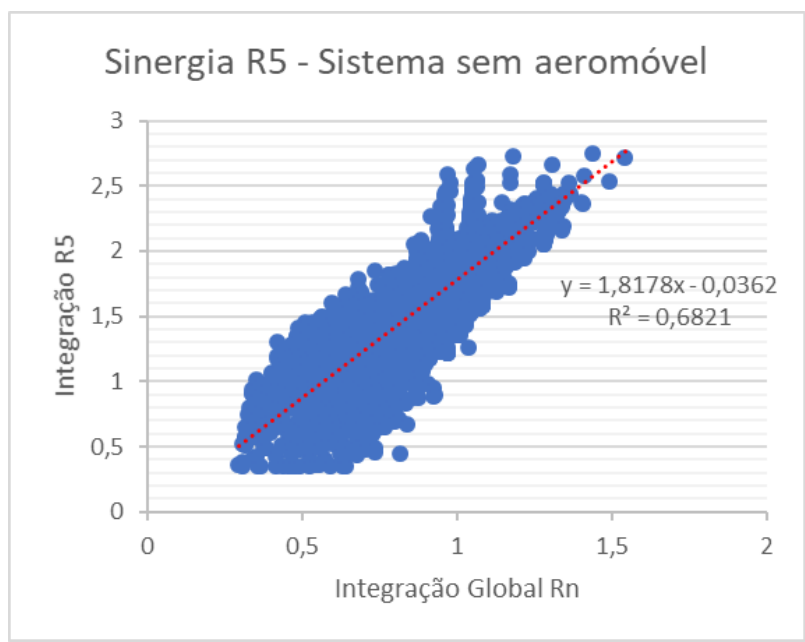

Figura 15: Integração local R3 com aeromóvel.

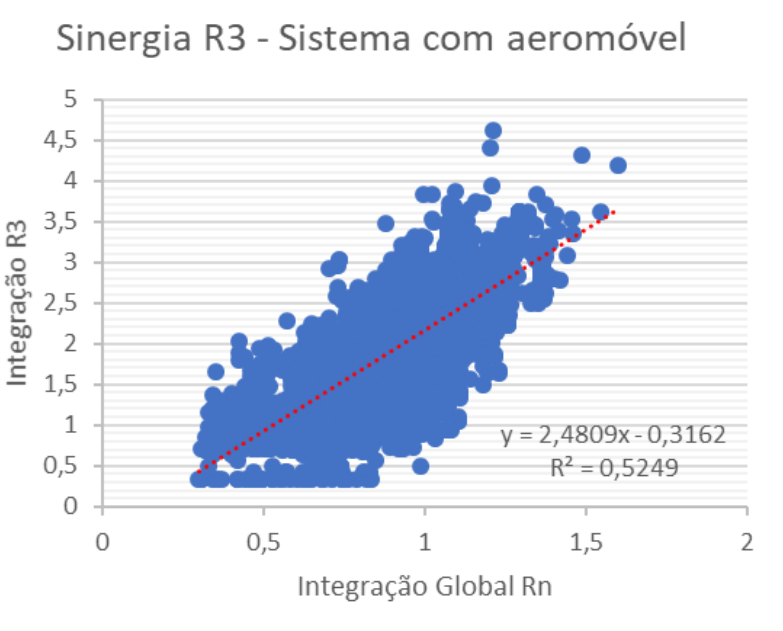

Figura 17: Integração local R5 com aeromóvel.

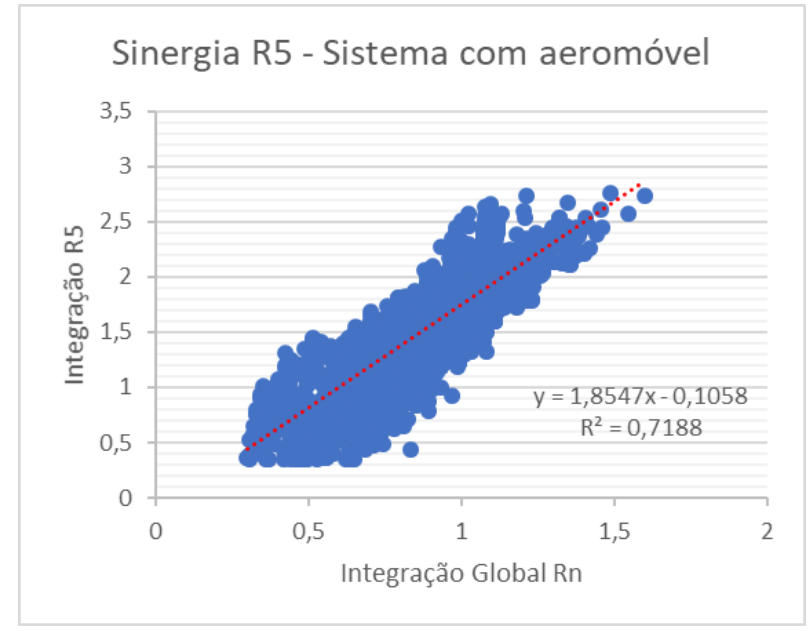

Fonte: Os autores (2018).

Observa-se que a implantação do aeromóvel melhora a Sinergia do sistema tanto para o raio local 3 quanto para o raio local 5. No caso do raio 3, o valor do $R^{2}$ passou de 0,4915 (Figura 14) para 0,5249 (Figura 15), um aumento de $6,8 \%$ e, no caso do raio 5 , o valor do $R^{2}$ passou de 0,6821 (Figura 16) para 0,7188 (Figura 17), um aumento de $5,4 \%$. Os aumentos verificados significam que o sistema passa a ter uma maior correlação entre linhas axiais que apresentam boa Integração local (nível de bairro) com a Integração global (nível municipal). Pela sua relação com potenciais de movimento, uma maior Sinergia do sistema significa que a parte mais integrada globalmente também será do núcleo de bairro local o que repercute no movimento de pessoas pelo sistema, o que trará além de uma Integração do bairro com a cidade, a possibilidade de que o movimento do bairro seja compatível ao do sistema da cidade.

\section{CONCLUSÃO}

O presente artigo avaliou as mudanças configuracionais no sistema do município de Canoas que adviriam da implantação do aeromóvel, um grande projeto de transporte público municipal que teve sua implantação paralisada. A avaliação teve como base a Teoria e Métodos da Sintaxe Espacial, e foi feita por meio de mapas axiais para duas situações distintas, antes e após da implantação do aeromóvel. A avaliação do sistema por meio de mapas axiais contemplando as duas situações permite a determinação das mudanças nas medidas sintáticas avaliadas, Integração Global, Integração Local (R3) e na Sinergia (R3 e R5) do sistema, ou seja, analisar a acessibilidade e os núcleos de centralidade da cidade e dos bairros afetados pelo projeto. 
A Integração global está associada à acessibilidade geral de todos os espaços do sistema, ou seja, a quão fácil ou quão difícil é de se chegar a um local partindo-se de qualquer ponto da cidade. O sistema analisado teve um ganho na Integração global de aproximadamente 5\%, com a média dos valores de Integração para as linhas axiais do sistema passando de 0,87 para 0,91, e os valores máximos passaram de 1,53 para 1,62. Na situação pré-aeromóvel, o bairro Guajuviras, um dos bairros mais pobres e mais populosos de Canoas é, também, o bairro mais segregado do sistema e o que apresenta os maiores ganhos de acessibilidade (o ganho na média da Integração global para o bairro Guajuviras foi de quase $11 \%$ ). Dada a maior dependência da população de baixa renda de transporte público, associada ao fato de habitarem em bairros mais segregados e mais distantes do sistema, este projeto poderia se traduzir em melhorias concretas, como significativa redução de tempo de percurso, que está associada a mais tempo livre para lazer, estudos e atividades domésticas. Ainda, a uma menor dependência de veículos privados individuais ou transporte alternativo, que se traduz em menor comprometimento de renda com transporte. Como há uma correlação entre segregação espacial e prosperidade, sendo as áreas mais integradas, mais prósperas (VAUGHAN, 2007), a diminuição da profundidade de bairros que apresentam baixos indicadores sociais é desejável no âmbito do planejamento urbano.

Além da medida de Integração global, também foi avaliada a medida de Integração local R3, que apresenta correlação positiva com o movimento de pedestres. Ela está relacionada a percursos curtos pelo sistema, como dentro do bairro, no comércio local ou até a escola e uma melhoria significativa na situação em que o aeromóvel se encontrasse implantado. O maior destaque é o surgimento de uma centralidade local dentro do bairro Guajuviras, até então inexistente, que poderia se configurar como uma região de maior vitalidade, com mais pessoas circulando e maior desenvolvimento de comércio dado o aumento no potencial de movimento local, funcionando como uma centralidade de bairro.

Finalmente avaliou-se a Sinergia do sistema para entre a integração global com dois raios locais, R3 e R5, sendo que ambos apresentaram melhora significativa. A Sinergia está relacionada a quanto o sistema apresenta vias que são integradas tanto local quanto globalmente, e o quanto o potencial de movimento de pedestres local (de vias mais integradas localmente) está associado ao potencial de movimento de pedestres global (de vias mais integradas globalmente). Correlações mais altas significam a existência de poucas situações em que uma via é muito integrada em uma dada escala (por exemplo, R3 ou R5), mas pouco integrada em outra (por exemplo, global) o que poderia indicar núcleos segregados da cidade. Indica uma coesão do sistema, sem tantas discrepâncias. No caso do sistema avaliado, o aumento da Sinergia quer dizer que para este sistema ocorreriam melhorias na acessibilidade de uma forma consistente.

A avaliação configuracional da cidade de Canoas com a implantação do aeromóvel demonstrou que, caso o projeto fosse implantado, poderia trazer melhorias significativas para a cidade em termos de acessibilidade e melhoria nos tempos de deslocamento da população que hoje se encontra mais segregada espacialmente (isto é, mais distante do resto do sistema). Outro ponto a ser destacado é que as melhorias das medidas de Integração do sistema são consideradas significativas pelo tamanho da cidade, bem como de sua malha viária, uma vez que Canoas é a quarta maior cidade do RS tanto em PIB anual quanto em população. Ao contrário da implantação de um sistema de transporte público por ônibus, este modal incorreria em uma real diminuição dos passos topológicos e da profundidade do sistema como um todo.

A literatura tem associado a segregação espacial involuntária à piora dos indicadores sociais, em oposição a indicadores positivos relacionados às áreas mais integradas espacialmente, como aumento na circulação de pessoas, facilidade de acesso a serviços públicos, maior vitalidade das ruas, fomento do comércio e diminuição da criminalidade. Assim, mudanças proporcionadas por obras de infraestrutura urbana (medidas e verificadas espacialmente) podem se traduzir em benefícios reais em outras esferas da vida social. No caso da implantação do aeromóvel em Canoas, o estudo configuracional mostrou que aconteceriam mudanças positivas na acessibilidade e integração de áreas periféricas; correlacionar (mesmo preliminarmente) essas medidas sintáticas a dados empíricos permite inferir que haveria grande possibilidade de indução de melhorias práticas no sistema analisado, o que poderia se converter em reais melhoras para a cidadania das populações afetadas. No entanto, ressalta-se o caráter hipotético desta avaliação que, embora baseada em dados reais (medidos pelas ligações entre espaços), não pretende capturar toda a complexidade urbana. Finalmente, reforça-se que, conforme verificado estudo realizado, a Sintaxe Espacial permite a visualização dos impactos (positivos ou negativos) das alterações na configuração espacial em escala municipal, podendo ser empregada com esta finalidade a fim de gerar modelos simulatórios para verificação do potencial de cada mudança. 


\section{REFERÊNCIAS}

AEROMÓVEL. Projeto aeromóvel de Canoas. [s.d.]. Disponível em: <http://www.aeromovel.com.br/cases/canoas/>. Acesso em: 13 nov. 2018.

BRASIL. Lei No 12.587, de 3 de janeiro de 2012 - institui as diretrizes da Política Nacional de Mobilidade Urbana. Diário Oficial da República Federativa do Brasil, Brasília, Brasil, jan. 2012.

CARVALHO, C. R.; PEREIRA, R. M. H. Texto para discussão: Gastos das famílias brasileiras com transporte urbano público e privado no Brasil: uma análise da pof 2003 e 2009. Brasília: IPEA, 2012. Disponível em: <http://www.ipea.gov.br>. Acesso em: 12 nov. 2018.

CORTELETTI, L. Efeitos configuracionais do sistema de transporte público: a extensão do Trensurb até Novo Hamburgo - RS. Dissertação (Mestrado em Planejamento Urbano e Regional). Faculdade de Arquitetura, Universidade Federal do Rio Grande do Sul, Porto Alegre.

CUTTINI, V. Spazio urbano e movimento pedonale Uno studio sull'ipotesi configurazionale. Cybergeo: european journal of geography, [s. I.], v. 111, 1999. Disponível em: <https://arpi.unipi.it/retrieve/handle/11568/161011/159631/cyber 1.pdf>. Acesso em: 12 jun. 2018.

FUNDAÇÃO DE ECONOMIA E ESTATÍSTICA (FEE). PIB dos municípios do RS em 2015: municípios industriais foram os mais afetados em ano de crise. Porto Alegre, 2017. Disponível em : https://www.fee.rs.gov.br/indicadores/pibrs/municipal/destaques/. Acesso em : 12 jun. 2018.

GIL, J. et al. The space syntax toolkit: Integrating depthmapX and exploratory spatial analysis workflows in QGIS The space syntax toolkit: Integrating depthmapX and exploratory spatial analysis workflow. In: $10^{\text {TH }}$ INTERNATIONAL SPACE SYNTAX SYMPOSIUM. Proceedings of ..... Londres, 2015. p.1-12

GIL, J. Examining "Edge Effects": Sensitivity of Spatial Network Centrality Analysis to Boundary Conditions. In: $10^{\mathrm{TH}}$ INTERNATIONAL SPACE SYNTAX SYMPOSIUM. Proceedings of ..... Londres, 2015. p.1-16.

GIL, J. Integrating public transport networks in the axial model. In: $8^{\text {TH }}$ INTERNATIONAL SPACE SYNTAX SUMPOSIUM 2012, Santiago, Chile. Proceedings of ..... Santiago, Chile

HOLANDA, F. O espaço de exceção. 2. ed. Brasília: FRHB, 2002.

HILLER, B.; HANSON, J. The Social Logic of Space. 1a edição ed. Nova lorque: Cambridge University Pr, 1984.

HILLIER, B. et al. Natural movement. Environment and planning B, [s. I.], v. 20, p. 29-66, 1993.

HILLIER, B.; VAUGHAN, L. The city as one thing. Progress in Planning, [s. I.], v.67, p 205-230, 2007. Disponível em: $<$ http://discovery.ucl.ac.uk/3272/>

INSTITUTO BRASILEIRO DE GEOGRAFIA E ESTATÍSTICA (IBGE). Canoas. Rio de Janeiro, 2018. Disponível em: <https://cidades.ibge.gov.br/brasil/rs/canoas/panorama>. Acesso em: 12 jun, 2018.

JIANG, B. Ranking Spaces for Predicting Human Movement in an Urban Environment. International Journal of Geographical Information Science, [s. I.], v. 23, n. 7, p. 1-11, 2009.

KLARQVIST, B. A Space Syntax Glossary. Nordisk Arkitekturforskning, [s. I.], v. 2, p. 11-12, 1993.

MARICATO, E. Metrópole, legislação e desigualdade. Estudos Avançados, [s. I.], v. 17, n. 48, p. 151-167, 2003. Disponível em: <http://www.scielo.br/pdf/ea/v17n48/v17n48a13.pdf>. Acesso em: 20 fev. 2018.

RIGATTI, D. Do espaço projetado ao espaço vivido. Tese de Doutorado. Universidade de São Paulo (USP), São Paulo, 1997.

RIGATTI, D; ZAMPIERI, F. L. Mapas da região metropolitana de Porto Alegre. Porto Alegre, PROPUR/UFRGS, 2009.

TURNER, A. Angular Analysis. In: $3^{\text {TH }}$ INTERNATIONAL SPACE SYNTAX SYMPOSIUM. Proceedings of ..... Atlanta, Estados Unidos, 2011, p. 30.1-30.11 Disponível em: http://discovery.ucl.ac.uk/35952/, Acesso em : 20 fev. 2018

UCL SPACE SYNTAX. Axial synergy. Londres, 2019. Disponível em :< http://otp.spacesyntax.net/term/axial-synergy/>. Acesso em: 20 fev. 2018.

UGALDE, C. M. Movimento e hierarquia espacial na conurbação: o caso da região metropolitana de Porto Alegre. Tese (doutorado). Universidade Federal do Rio Grade do Sul, Programa de Pós-Graduação em Planejamento Urbano e Regional (PROPUR), Porto Alegre, Brasil, 2013.

VAN NES, A. et al. How spaces syntax can be applied in regenerating urban areas: Applying macro and micro spatial

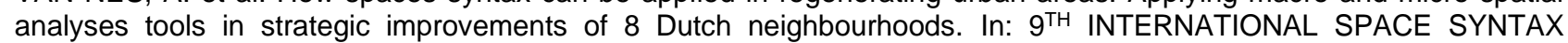
SYMPOSIUM. Proceedings of ..... Seul, Coréias, 2013, p.1-13

VAUGHAN, L. The spatial syntax of urban segregation. Progress in Planning, [s. I.], v. 67, n. 3, p. 205-294, 2007.

YOUNG, C. E. F.; AGUIAR, C.; POSSAS, E. Custo econômico do tempo de deslocamento para o trabalho na Região Metropolitana do Rio de Janeiro. Revista Econômica, Niterói, RJ, Brasil, v. 15, n. 2, 2013, p. 9-22. 
ZAMPIERI, Fábio Lúcio; DIOGENES, Mara Chagas; RIGATTI, Décio. Modelo De Predição De Fluxo De Pedestres Aplicado a Ambientes Urbanos. In: XXI ANPET 2007, Rio de Janeiro. Anais... Rio de Janeiro

ZAMPIERI, Fábio Lúcio Lopes. Modelo Estimativo de Movimento de Pedestres Baseado em Sintaxe Espacial, Medidas de Desempenho e Redes Neurais Artificiais. 2006. Dissertação (mestrado). Programa de Pós-Graduação em Planejamento Urbano e Regional, Faculdade de Arquitetura, Universidade Federal do Rio Grande do Sul (UFRGS), Porto Alegre, p. 274, 2006.

ZAMPIERI, Fábio Lúcio Lopes. O Fenômeno Social do Movimento de Pedestres em Centros Urbanos. 2012. Tese (doutorado). Programa de Pós-Graduação em Planejamento Urbano e Regional, Faculdade de Arquitetura, Universidade Federal do Rio Grande do Sul (UFRGS), Porto Alegre, p. 918, 2012.

\section{NOTAS}

1 Embora "Sintaxe do Espaço" seja uma tradução mais correta para o português da terminologia inglesa Space Syntax (HILLIER et al. 2016), este trabalho utiliza a expressão "Sintaxe Espacial", termo consolidado por pesquisadores de referências na área, como Holanda (2002), Rigatti (1997) e Oliveira (2016), entre outros.

2 Disponível em http://otp.spacesyntax.net/applying-space-syntax/urban-methods-2/representations-of-space/ acesso em 28 de abril de 2019.

${ }^{3}$ Disponível em http://canoas.web7033.uni5.net/canoas-em-dados/, acesso em 28 de abril de 2019.

${ }^{4}$ Disponível em http://www.aeromovel.com.br/cases/canoas/, acesso em 28 de abril de 2019.

${ }^{5}$ A Fundação Estadual de Planejamento Metropolitano e Regional (METROPLAN) é o órgão responsável pela elaboração e coordenação de planos, programas e projetos do desenvolvimento regional e urbano do Estado do Rio Grande do Sul, assumindo, ainda, o planejamento, coordenação, fiscalização e gestão do Sistema Estadual de Transporte Metropolitano Coletivo de Passageiros. (Disponível em: http://www.metroplan.rs.gov.br/conteudo/1598/?A Metroplan. Acesso em 05 de fevereiro de 2020).

NOTA DO EDITOR $\left({ }^{*}\right)$ : O conteúdo do artigo e as imagens nele publicadas são de responsabilidade do(s) autor(es). 